\title{
FEATURES OF SILOS CALCULATIONS AT ASYMMETRIC WIND LOAD BY USING THE MOMENTLESS THEORY
}

\author{
Oleksandr LAPENKO, Anton MAKHINKO, Natalia MAKHINKO
}

\begin{abstract}
The paper deals with the features of silos calculations as shells of rotation under asymmetric semi-uniform load. In accordance with the equation of equilibrium by using the momentless theory, the expressions for maximum value of linear longitudinal efforts in radial and meridional (longitudinal) direction and linear shearing force have been obtained. Analysis of design factor series of linear efforts and shearing force has been carried out in the paper. The opportunity of using the momentless theory to evaluate changes of linear efforts in radial direction and shearing forces has been presented. The quantitative assessment of a normal tension in laminas of silo body from the influence of maximum linear efforts and their connection with the tension from the pressure of the bulk material at the top of the capacity have been given. Full radial and contacting displacements of the capacity in the plane of cross section from the element of the wind load have been defined.
\end{abstract}

Keywords: aerodynamics; cylindrical silo; internal forces; membrane theory of shells; radial displacements; wind loads

\section{INTRODUCTION}

Definition of the state of tension of the silos constructions is an important engineering problem. Calculation of the construction depends on the character of the external load. The main asymmetric semi-uniform load for storage containers is wind load. It is radially applied external load that is evenly distributed along the length of capacity, but it is changeable in the cross-section according to the corresponding law.

Similar problems were studied earlier, but they have a rather conditional character towards the nature of the wind load or they refer to the shell calculations in general without the emphasis on the deflective mode of distinct elements [2, 3].

\subsection{Defining the Unsolved Aspects of the Problem}

According to the general theory of shell rotation it is known that any load can be decomposed in trigonometric series of the finite length $[4,5]$, for which functional connections between parameters of the load and the deflective mode already exist. By contrast, the wind load is well approximated near cosines. Decomposition of the wind load into finite trigonometric series will simplify the calculation by examining every element separately.

\subsection{The Aim of the Article}

The aim of this paper is to calculate silos and analysis of displacement taking into consideration deflective mode of vertical stiffening ribs that receive wind load together with the body and take part in transferring arising efforts on the basis.

\section{RESEARCH RESULTS}

According to the design norms of different countries of the world, including NBS (National Building Standards) [1], uneven distribution of the wind load around the perimeter of cylindrical capacities is described by the function of aerodynamic coefficient $C_{a e r}(\varphi)$. This function is represented in the normative literature in tables (graphs) $[6,7]$ or analytically using decimal logarithms $[8,9]$. It is the cause of many inconveniences in capacity calculations. It can be eliminated by decomposing the function $C_{a e r}(\varphi)$ into trigonometric series.

$$
\begin{aligned}
& C_{a e r}(\varphi)=a_{0}+a_{1} \cos (\varphi)+a_{2} \cos (2 \varphi)+ \\
& \ldots+a_{k} \cos (k \varphi)+\ldots+a_{m} \cos (m \varphi) .
\end{aligned}
$$

There are graphs and diagrams of the aerodynamic coefficient correspondingly in Fig. 1 when it is decomposed into 5-7 elements. In Tab. 1, there are coefficients of this decomposition, computed by the method of the least square according to the graph of norms [1].

Table 1 Quantities of coefficients $a_{k}$ during the series development $C_{a e r}(\varphi)$ according to $\cos (k \varphi)$

\begin{tabular}{|c|c|c|c|c|c|c|}
\hline № & $a_{0}$ & $a_{1}$ & $a_{2}$ & $a_{3}$ & $a_{4}$ & $a_{5}$ \\
\hline 5 & -0.380 & 0.326 & 0.686 & 0.478 & 0.040 & H \\
\hline 6 & -0.380 & 0.337 & 0.686 & 0.489 & 0.040 & -0.114 \\
\hline 7 & -0.378 & 0.337 & 0.690 & 0.489 & 0.044 & -0.114 \\
\hline 8 & -0.378 & 0.338 & 0.690 & 0.490 & 0.044 & -0.113 \\
\hline 9 & -0.377 & 0.338 & 0.692 & 0.490 & 0.046 & -0.113 \\
\hline 5 & $a_{6}$ & $a_{7}$ & $a_{8}$ & $\xi_{p}$ & $\xi_{h}$ & $\xi_{s}$ \\
\hline 6 & $\mathrm{H}$ & H & H & 8.01 & 0.77 & 1.32 \\
\hline 7 & $\mathrm{H}$ & $\mathrm{H}$ & $\mathrm{H}$ & 5.27 & 0.72 & 1.37 \\
\hline 8 & -0.048 & $\mathrm{H}$ & $\mathrm{H}$ & 3.63 & 0.70 & 1.42 \\
\hline 9 & -0.048 & -0.016 & $\mathrm{H}$ & 2.88 & 0.70 & 1.44 \\
\hline 5 & -0.046 & -0.016 & -0.021 & 1.65 & 0.69 & 1.45 \\
\hline
\end{tabular}

From the drawing we can see that 5 or 6 elements in series are sufficient for practical calculations accuracy. The attention needs to be directed to the recommendation norms [1] which are not the only ones, for example [10], which, respectively, influence the quantitative assessment of series coefficients (1). However, this question requires further 
research of the wind effect both on separate capacities and capacities as a part of silos stock.

Decomposition of aerodynamic coefficient and wind load, respectively, into finite trigonometric series allows a significant simplification of the solution of the calculation problem of cylindrical capacities, since in this case calculation can be carried out for every element of the load separately. Following is the equation of equilibrium for capacity according to the momentless theory [11]

$$
\begin{aligned}
& \frac{D_{w}}{2} \frac{\partial N_{p, k}(x)}{\partial x}+\frac{\partial S_{k}(x, \varphi)}{\partial \varphi}=0, \\
& \frac{\partial N_{h, k}(\varphi)}{\partial \varphi}+\frac{D_{w}}{2} \frac{\partial S_{k}(x, \varphi)}{\partial x}=0, \\
& N_{h, k}(\varphi)=\frac{W_{k} D_{w}}{2},
\end{aligned}
$$

where $N_{h, k}$ and $N_{p, k}$ are linear longitudinal efforts in radial and meridional (longitudinal) directions; $S_{k}$ is a linear shearing force; $A_{k}$ is an amplitude value of $k$ element.

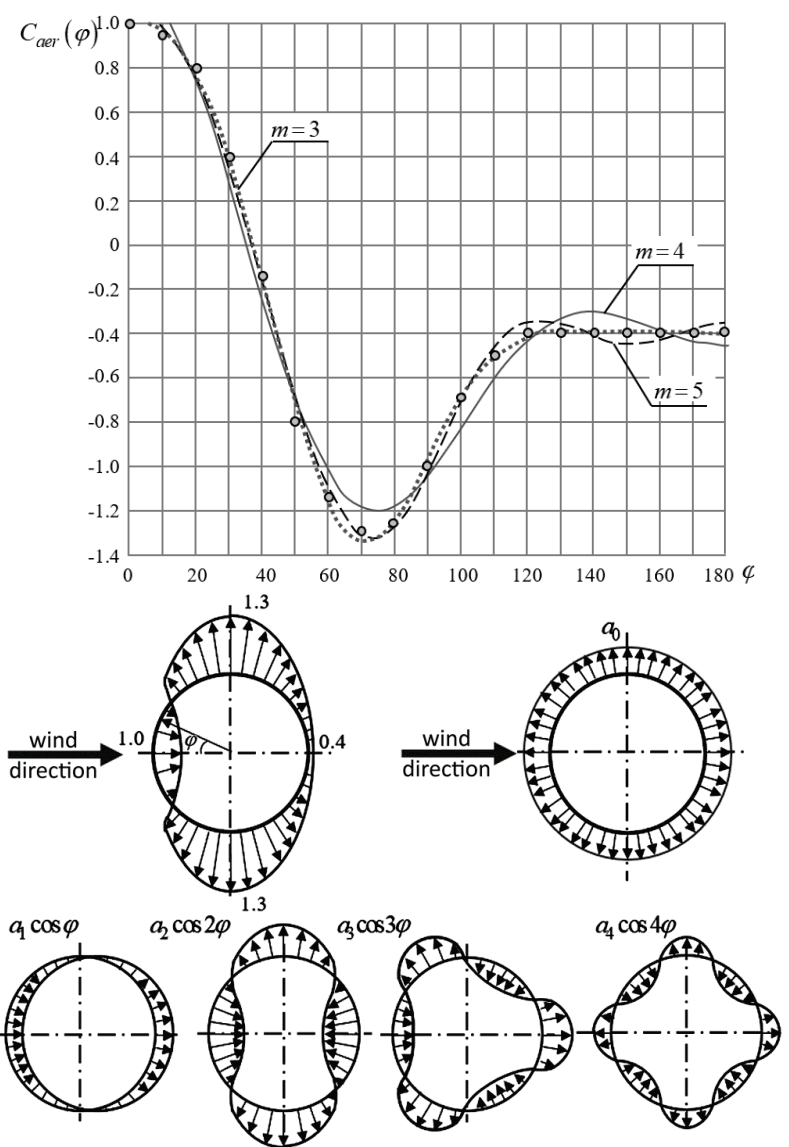

Figure 1 Series development of the aerodynamic coefficient of the wind load

From the system of differentiate Eqs. (2) we will get unknown efforts

$$
S_{k}(x, \varphi)=\left(k A_{k} x+C_{1}\right) \sin (k \varphi),
$$

$$
N_{p, k}(x)=\left[\frac{k\left(k A_{k} x^{2}-C_{1} x\right)}{D_{w}}+C_{2}\right] \cos (k \varphi),
$$

where $C_{1}$ and $C_{2}$ are arbitrary constants, which are defined from the boundary condition $N_{p, k}(x) \wedge S_{k}(x, \varphi)=0$ when $x$ $=0$, if to count $x$ from the top of the capacity.

When we find out that arbitrary constants under the given boundary conditions are equal to zero, we get

$$
\begin{aligned}
& S_{k}(x, \varphi)=k A_{k} x \sin (k \varphi), \\
& N_{p, k}(x, \varphi)=\frac{k^{2} A_{k} x^{2} \cos (k \varphi)}{D_{w}}, \\
& N_{h, k}(\varphi)=A_{k} D_{w} \cos (k \varphi) / 2 .
\end{aligned}
$$

Full efforts from the influence of the wind load will be expressed as a sum of Eqs. (5)-(7) according to the accepted amount of $m$ elements of trigonometric series (1). After this, it is easy to get the maximum value of efforts $S_{\max }(x)$, $N_{p, \text { max }}(x)$ and $N_{h \text {,max. }}$ It is likely that functions $N_{p}(x, \varphi)$ and $N_{h}(\varphi)$ peak when $\varphi=0$, therefore for $N_{p, \max }(x)$ and $N_{h, \text { max }}$ we can write down

$$
\begin{aligned}
& N_{p, \text { max }}(x)=w_{p} x^{2} \xi_{p} / D_{w}, \quad \xi_{p}=\sum_{k=0}^{m} k^{2} a_{k}, \\
& N_{h, \text { max }}=w_{p} D_{w} \xi_{h}, \quad \xi_{h}=\frac{1}{2} \sum_{k=0}^{m} a_{k},
\end{aligned}
$$

where $w_{p}$ is a design value of the wind load excluding the coefficient $C_{a e r}$.

According to the classic rules of the search of the function extremum, the maximum condition of $\varphi_{\max }$ of the effort $S_{\max }(x)$ is established. Calculations show that depending on the number of elements of the $m$ series (1) $\varphi_{\max }$ varies from $37^{\circ}$ to $41^{\circ}$, which correspond to the meaning of the coefficient $\xi_{s}=1.32-1.45$ (Tab. 1). For maximum effort $S_{\max }$ we have an equation

$$
S_{\max }(x)=w_{p} x \xi_{s}, \quad \xi_{s}=\sum_{k=0}^{m} k a_{k} \sin \left(k \varphi_{\max }\right)
$$

By examining in details expressions from (8) to (10), we can pay attention to a rather wide diapason of the change of the coefficient $\xi_{p}$ compared to coefficients $\xi_{h}$ and $\xi_{s}$, depending on the number of $m$ elements of the series $C_{a e r}(\varphi)$. At the same time, if coefficients $\xi_{h}$ and $\xi_{s}$ approach to some constant value, the same cannot be said about the coefficient $\xi_{p}$. It is explained by limitation of the momentless theory which is prone to more "smooth" change of external load; however, if the parameter $m$ increases, we will have another nature.

Efforts $S(x, \varphi)$ and $N_{h}(\varphi)$ are less dependent from the smooth change of the load (outside of the border effect), since the energy of bending (the capacity is under the cross 
bend) mainly received by vertical stiffener ribs. Therefore, it makes sense that it is some boundary value for the coefficient $\xi_{p}$, which allows finding acceptable results using the Eq. (8). Basis of such value is given in the next paragraph of this section.

Numerical assessment can be given to normal tensions in laminas of the body under efforts $N_{h, \max }$ and $S_{\max }$ to understand how they correlate with tensions from the pressure of the bulk material when $x=H_{w}$. The maximum value of the diameter is set to $D_{w}=40 \mathrm{~m}$ and the height to $H_{w}$ $=40 \mathrm{~m}$ of the capacity and it is taken into account that the design value of the wind load $w_{p}$ excluding aerodynamic coefficient $C_{a e r}$ rarely exceeds value of $1 \mathrm{kPa}$. Consequently, we get that even when $t_{w}=1 \mathrm{~mm}$ hoop tensions $N_{h, \text { max }} / t_{w}$ does not exceed $3 \mathrm{kN} / \mathrm{cm}^{2}$, and the sheer stress $S_{\max }(x) / t_{w}-6$ $\mathrm{kN} / \mathrm{cm}^{2}$. If the designed situation, which connected to the wind load, is current for the empty capacity, these efforts are not supplement spectrum of tensions from the pressure of the bulk material and we can neglect them in calculations.

The capacity displacement can be defined because of the load $W_{k}=A_{k} \cos (k \varphi)$. In order to do this, geometric equations of the cylindrical shell assuming non-stretchability of its middle line in annular direction and absence of the shear line in it are used. Taking into account (4), we can write down

$$
\begin{aligned}
& \frac{\partial u(x, \varphi)}{\partial x}=\frac{N_{p, k}(x, \varphi)}{E t_{w, e f}}, \\
& \frac{\partial v(x, \varphi)}{\partial \varphi}+w(x, \varphi)=0, \\
& \frac{2}{D_{w}} \frac{\partial u(x, \varphi)}{\partial \varphi}+\frac{\partial v(x, \varphi)}{\partial x}=0 .
\end{aligned}
$$

Conditional thickness of the $t_{e f, x}$ capacity in the crosssection, which was input in the first expression of the Eq. (11), is taking into account that the change of the longitudinal deformation of the capacity occurs due to both deformations of vertical stiffener ribs and deformations of borders of the body. This defines conditional thickness using actual thickness of the capacity's body and correlation of planes of the cross-section of vertical stiffener ribs and the body of the capacity

$$
t_{e f, x}=t_{w}+\frac{A_{p} n_{p}}{\pi D_{w}}=t_{w}\left(1+\frac{A_{p} n_{p}}{\pi D_{w} t_{w}}\right)=t_{w}\left(1+\alpha_{w p}\right)
$$

where $\alpha_{w p}=A_{p} n_{p} /\left(\pi D_{w} t_{w}\right)$ is the ratio of planes of crosssections of all vertical stiffener ribs and the wall of the capacity.

If all dependences that are needed are substituted and a series of algebraic manipulations is done, we get

$$
\begin{aligned}
& \frac{\partial u(x, \varphi)}{\partial x}=\frac{k^{2} x^{2}}{E t_{w}} \frac{1}{D_{w}\left(1+\alpha_{w p}\right)} A_{k} \cos (k \varphi), \\
& \frac{\partial v(x, \varphi)}{\partial \varphi}+w(x, \varphi)=0, \\
& \frac{2}{D_{w}} \frac{\partial u(x, \varphi)}{\partial \varphi}+\frac{\partial v(x, \varphi)}{\partial x}=0,
\end{aligned}
$$

where $u, v$ and $w$ are longitudinal, annular and radial displacements of the body.

Integrating by $x$ and $\varphi$ and defining arbitrary constants under the condition $x=H_{w}-u(\cdot)=v(\cdot)=w(\cdot)=0$, after arithmetic manipulations and similar consolidation, we get (to reduce it, it is denoted by $y=x / H_{w}$ ):

$$
\begin{aligned}
& u_{k}(y, \varphi)=\frac{G_{H}}{2 \Delta_{w}}\left(1-y^{3}\right) a_{k} k^{2} \cos (k \varphi), \\
& v_{k}(y, \varphi)=G_{H}\left(y-y^{4} / 4-0.75\right) a_{k} k^{3} \sin (k \varphi), \\
& w_{k}(y, \varphi)=-G_{H}\left(y-\frac{y^{4}}{4}-\frac{3}{4}\right) a_{k} k^{4} \cos (k \varphi),
\end{aligned}
$$

where $y=x / H_{w}$ is a non-dimensional high-rise level, $G_{H}$ is a conventional deflection

$$
G_{H}=\frac{2 w_{p} H_{w}^{2} \Delta_{w}^{2}}{3\left(1+\alpha_{w p}\right) E t_{w}} .
$$

For full displacements of the capacity's body (radial or linear) in the plane of the cross-section we get an equation

$$
\begin{aligned}
& w_{\Sigma, k}(y, \varphi)=G_{H}\left(y-\frac{y^{4}}{4}-\frac{3}{4}\right) \times \\
& \times a_{k} k^{4} \sqrt{\cos ^{2}(k \varphi)+\frac{1}{k^{2}} \sin ^{2}(k \varphi)} .
\end{aligned}
$$

Maximum values of all displacements under load $W_{k}=A_{k} \cos (k \varphi)$ are realized when $y=0$, that means at the top of the capacity

$$
\begin{aligned}
& u_{k, \max }=\frac{G_{H}}{2 \Delta_{w}} a_{k} k^{2} \cos (k \varphi), \\
& w_{k, \max }=\frac{3 G_{H}}{4} a_{k} k^{4} \sqrt{\cos ^{2}(k \varphi)+\frac{1}{k^{2}} \sin ^{2}(k \varphi)} .
\end{aligned}
$$

Full displacements from the influence of the wind load are analogous to full efforts. It means adding by using separate harmonicas $k$. Mainly, we are interested in maximum values for $u(\bullet)$ and $w_{\Sigma}(\bullet)$ when $\varphi=0$, then after simplifications we get 


$$
\begin{aligned}
& u_{\max }=\frac{G_{H}}{2 \Delta_{w}} \xi_{p}, \\
& w_{\Sigma, \max }=\frac{3 G_{H}}{4} \xi_{w}, \\
& \xi_{w}=\sum_{k=0}^{m} k^{4} a_{k} .
\end{aligned}
$$

According to the data from Tab. 1, numeric value of the coefficient $\xi_{w}$ corresponds to $m=5-\xi_{w} \approx 60.3 ; \mathrm{m}=6-\xi_{w} \approx$ $-10.1 ; m=7-\xi_{w} \approx-71.2 ; m=8-\xi_{w} \approx-109 ; m=9-\xi_{w} \approx$ -192 .

Analysis of the obtained results raises doubt about the accuracy of the value of full displacements.

It must be pointed out that the results, which were obtained above, refer to capacities that have constant thickness of body and ribs in height. In case of the changeable thickness, we have to decompose the exponent $\exp \left[\varepsilon_{w}\left(x / H_{w}\right)\right]$ into the power series, restraining first four elements when $\varepsilon_{w} \leq 1.5$. Meanwhile, to describe functional dependences $t_{w}(x)$ and $t_{p}(x)$, the one and the same exponent of the degree $\varepsilon_{w}$ must be used This claim is not too idealistic, since in real storage containers the thickness of vertical ribs and the wall simultaneously and monotonously decrease with the height.

\section{CONCLUSION}

1. To calculate cylindrical silos influenced by the wind load we offer to decompose function of the aerodynamic coefficient into the finite trigonometric series. It simplifies the solution significantly, since this calculation can be conducted for each element separately.

2. Coefficients of the given decomposition were calculated using the graph of norms.

3. According to the equation of equilibrium by using the momentless theory, expressions for maximum value of linear longitudinal efforts in radial and meridional (longitudinal) direction and linear shearing force were obtained.

4. The thesis about maximum shearing force was set up. Meaning of the incidence angle varies between $37^{\circ}-41^{\circ}$, depending on the number of components of the trigonometric series.

5. From the analysis of design factors series, the opportunity of using the momentless theory to evaluate changes of linear efforts in radial direction and shearing forces was presented. There is a boundary meaning of the design factor for linear efforts in meridional direction that allows finding acceptable results according to the proposed formula.

6. Quantitative assessment of the normal tension in laminas of the silos body (for maximum values of the diameter $D_{w}=40 \mathrm{~m}$ and the height $H_{w}=40 \mathrm{~m}$ ) was made from the influence of maximum linear efforts and their connection with tension from the pressure of the bulk material at the top of the capacity.
7. The expressions needed to define full radial and contacting displacements of the capacity in the plane of cross section from the element of the wind load were gotten.

8. Recommendations about the calculation of silos with changeable thicknesses of body laminas and stiffening ribs in height were given.

\section{REFERENCES}

[1] DBN V.1.2-2:2006. Systema zabezpechenniana diinostita bezpeky budivelnykh obiektiv. Navantazhennia i vplyvy. Normy proektuvannia, Ministry for Regional Development, Building and Housing of Ukraine, Kyiv, 2006, 83 p. (in Ukrainian)

[2] Kolkunov, N. (1972). Osnovyi raschyota uprugih obolochek: monografiya, Moscow: Vyisshaya shkola, 296 p. (in Russian)

[3] Korobov, L., Zharkov, A., \& Shernik, A. (2006). Dyimovyie $i$ ventilyatsionnyie trubyi vyisotoy 200-500 metrov, kak prostranstvennyie sooruzheniya, Moscow: Kompaniya Sputnik, 246 p. (in Russian)

[4] Flyugge, V. (1961). Statika i dinamika obolochek, Moscow: Gosudarstvennoe izdatelstvo literaturyi po stroitelstvu i arhitekture, 304 p. (in Russian)

[5] Goldenveyzer, A. (1976). Teoriya uprugih tonkih obolochek, Moscow: Nauka, 512 p. (in Russian)

[6] ASCE 7-10. (2010). Minimum Design Loads for Buildings and Other Structures, Virginia: American Society of Civil Engineers, $65 \mathrm{p}$.

[7] Schelokov, Ya., Duzhih, F., Osolovskiy, V., \& Ladyigichev, M. (2007). Sooruzhenie promyishlennyih dyimovyih trub: spravochnoe izdanie. Kniga 1. Konstruktsii, raschetyi, ekspertiza, Moscow: Teplotehnik, 336 p. (in Russian)

[8] Makhinko, A. (2012). Imovirnisnyi rozrakhunok bashtovykh opor zviazku, Poltava: PoltNTU, 410 p. (in Ukrainian)

[9] ISO 4354:2009 Wind Actions on Structures, Geneva: Switzerland: International Organization for Standardization, 2009, 68 p.

[10] Zdravkovich, M. (2003). Flow around Circular Cylinders, New York: Oxford Universiti press, Vol. 2, 314 p.

[11] Lessing, E., Lileev, A., \& Sokolov, A. (1970). Listovyie metallicheskie konstruktsii, Moscow: Stroyizdat, 490 p. (in Russian)

Authors' contacts:

Oleksandr LAPENKO, Doctor of Technical Sciences, Professor

National Aviation University

Kosmonavta Komarova 1, 03058 Kyiv, Ukraine

+380662006727, my-partner@ukr.net

Anton MAKHINKO, Doctor of Technical Sciences, Senior Scientist

ETUAL LLC

1, Bortnytska street, Petropavlivske, Boryspil district, Kiev, 08341, Ukraine

+380503272785, Pasargada1981@gmail.com

Natalia MAKHINKO, Candidate of Technical Science

National Aviation University

Kosmonavta Komarova 1, 03058 Kyiv, Ukraine

+380503045072, Pasargada1985@gmail.com 